\title{
Minimally invasive lumbar foraminotomy
}

\author{
Harel Deutsch, M.D. \\ Rush University Medical Center, Chicago, Illinois
}

\begin{abstract}
Lumbar radiculopathy is a common problem. Nerve root compression can occur at different places along a nerve root's course including in the foramina. Minimal invasive approaches allow easier exposure of the lateral foramina and decompression of the nerve root in the foramina. This video demonstrates a minimally invasive approach to decompress the lumbar nerve root in the foramina with a lateral to medial decompression.

The video can be found here: http://youtu.be/jqa61HSpzIA.

(http://thejns.org/doi/abs/10.3171/2013.V2.FOCUS13193)

KEY WORDS
radiculopathy $\quad \begin{gathered}\text { minimally invasive } \\ \text { decompression }\end{gathered}$
\end{abstract}

Manuscript submitted April 26, 2013.

Accepted May 30, 2013.

Please include this information when citing this paper: DOI: 10.3171/2013.V2.FOCUS13193.

Address correspondence to: Harel Deutsch, M.D., Rush University Medical Center, 1725 W. Harrison Street, Suite 855, Chicago, IL 60612.email: Harel_Deutsch@rush.edu. 